\title{
General Psychiatry Relevance of early intervention in Fahr's disease: understanding through a case study
}

\author{
Jamshed Ahmad, Bandna Gupta, Sujita Kumar Kar ${ }^{\odot}$
}

To cite: Ahmad J, Gupta B, Kar SK. Relevance of early intervention in Fahr's disease: understanding through a case study. General Psychiatry 2019;32:e100021. doi:10.1136/ gpsych-2018-100021

Received 09 0ctober 2018 Revised 11 January 2019 Accepted 14 January 2019
Check for updates

(C) Author(s) (or their employer(s)) 2019. Re-use permitted under CC BY-NC. No commercial re-use. See rights and permissions. Published by BMJ.

Department of Psychiatry, King George's Medical University, Lucknow, Uttar Pradesh, India

Correspondence to Dr Sujita Kumar Kar; drsujita@gmail.com

\section{SUMMARY}

Intracranial calcification may result from disturbances in calcium metabolism. It often remains asymptomatic, but may present with symptoms like seizure and neurological deficits. Correction of the underlying metabolic disturbance before damage of neuronal tissues due to intracranial calcification may be useful in preventing irreversible neurological deficits. This window period may be the crucial period that needs a thorough clinical evaluation and urgent intervention. We highlight the case of an adult woman with Fahr's disease presented with generalised tonic-clonic seizure. The management priorities were also discussed along with review of literature.

\section{INTRODUCTION}

Physiological intracranial calcifications often remain asymptomatic, detected incidentally by CT scans. It occurs in approximately $0.3 \%-1.5 \%$ of cases. ${ }^{1}$ Such calcifications are usually benign but may be caused by underlying pathology. The most common causes of pathological basal ganglia calcifications are hypoparathyroidism and pseudohypoparathyroidism. ${ }^{2}$ Other causes include pseudopseudohypoparathyroidism, hyperparathyroidism, hypothyroidism, familial idiopathic cerebral calcification (Fahr's syndrome), birth anoxia, carbon monoxide intoxication, lead poisoning, methotrexate therapy, Hastings-James syndrome, tuberous sclerosis, toxoplasmosis, cysticercosis, encephalitis caused by measles and chickenpox, Parkinsonism, vascular disease, radiation, Cockayne syndrome, post-infectious, AIDS (especially in children), Kearns-Sayre syndrome and other mitochondrial diseases, familial encephalopathies and Down's syndrome. ${ }^{3}$

Fahr's disease refers to a condition characterised by bilateral basal ganglia calcification. ${ }^{45}$ In Fahr's disease, there also occurs calcification of dentate nucleus. ${ }^{5}$ The most common manifestation in Fahr's disease is development of Parkinsonian features (extrapyramidal symptoms like hypokinesia, rigidity and tremor) ${ }^{6}$ and cognitive impairment. We present a case of an adult woman with Fahr's disease presented with generalised tonicclonic seizure without any other neurocognitive impairment.

\section{CASE REPORT}

A 35-year-old woman had presented in the outpatient services of psychiatry with multiple episodes of seizure for the past 6 years. The episodes of seizure were of generalised tonic-clonic type with a frequency of two to three episodes in a month. She was treated with phenytoin $300 \mathrm{mg} /$ day with partial control of seizures (frequency of seizures was decreased). However, non-adherence to treatment resulted in worsening of seizures. She was diagnosed with hypothyroidism 2 years ago and was on thyroxine supplementation $(50 \mu \mathrm{g} /$ day $)$. There was no history of any other medical illness. There was no history of psychiatric illness or substance use. Her family history was also uneventful. Premorbidly, she was well adjusted to life. She had expressed her concerns and worries related to seizure over the past few months prior to psychiatric consultation. Her distress was not persistent and often increased when seizures occurred more frequently. Current psychiatric evaluation did not reveal any significant psychopathology, other than apprehension about seizures.

Her general physical examination and systemic examination did not reveal any abnormality. There were no focal neurological deficits. Her cognition was intact. Lobar function tests also did not reveal any abnormality. The patient was investigated for seizure. CT scan of head revealed calcification in bilateral basal ganglia, frontal lobes and cerebellar hemispheres (figure 1). On the mental status examination, she had an anxious affect and worries related to persistent seizure. She was diagnosed with Fahr's disease. Her psychological symptoms were not persistent and mild in severity, so no psychiatric diagnosis was made. 

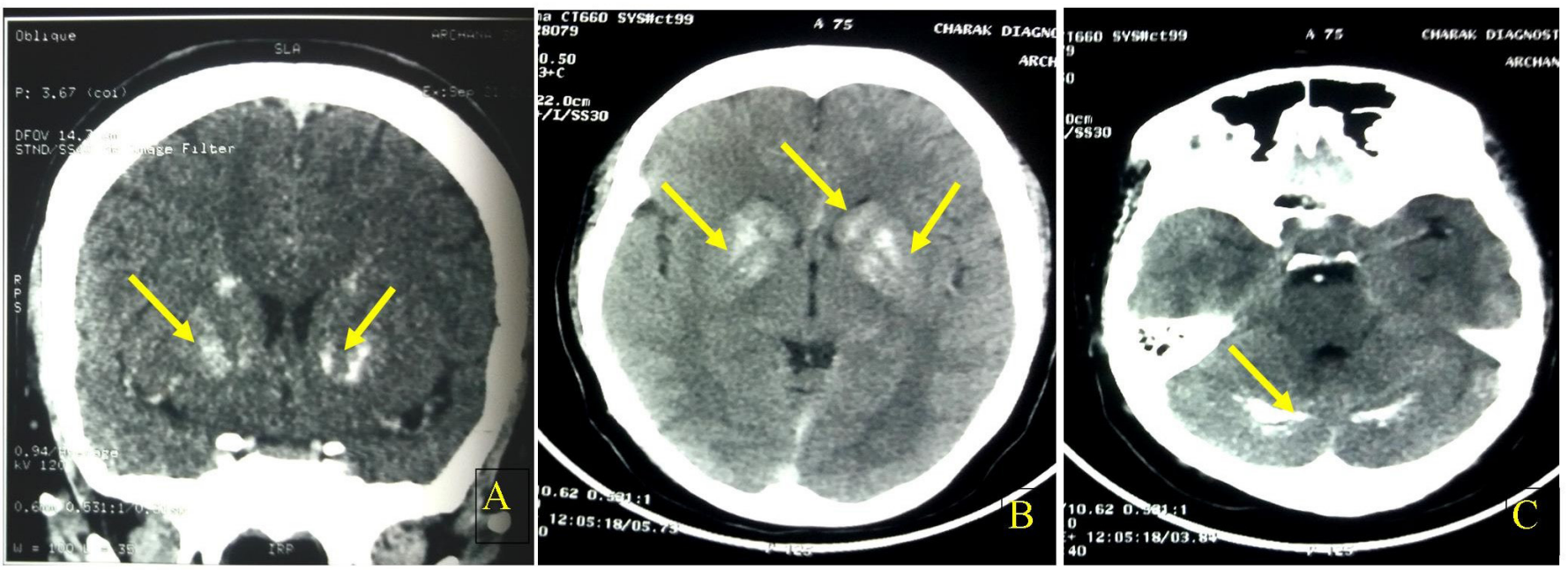

Figure 1 CT scan of brain showing calcification of bilateral basal ganglia (A, B), frontal lobe (B) and cerebellum (C).

It was planned to keep the patient on regular follow-up to see the evolution of symptoms over time. Her routine haemogram, liver function tests and kidney function tests were within normal limits. Her serum calcium (ionic) was $2.84 \mathrm{mg} \%$ (normal range: $4.5-5.5 \mathrm{mg} \%$ ). Parathormone (PTH) level was $14.37 \mathrm{pg} / \mathrm{mL}$ (normal range 12-88 pg/ $\mathrm{mL}$ ). There was increased phosphate level $(6.43 \mathrm{mg} \%$; normal range $2.5-4.5 \mathrm{mg} \%$ ) with normal level of serum albumin and alkaline phosphatase. Her seizure was treated with sodium valproate $600 \mathrm{mg} /$ day in divided doses. She was advised to remain adherent to treatment. Supportive counselling was done. The patient was referred to endocrinology unit for management of hypoparathyroidism. During follow-up, she reported adequate control of seizures and her psychological distress was also reduced significantly.

\section{DISCUSSION}

Our patient had only symptoms of seizures (generalised tonic-clonic type) which might be the manifestation of intracranial calcification. Her distress was a psychological reaction to persistent seizures. Phenytoin was partially effective in controlling the seizure. Treatment with valproate resulted in good control of seizure. Basal ganglia has important role in motor control. Dysfunction or damage to the integrity of basal ganglia manifests with features of Parkinson's disease. Our patient did not show any sign or symptom of Parkinson's disease despite calcification of bilateral basal ganglia.

Basal ganglia calcification in our patient was associated with calcifications in cerebellar hemispheres and frontal lobe. The patient did not exhibit any other symptoms clinically, other than the episodes of seizure. A study revealed that calcification of basal ganglia correlated with the duration of hypocalcaemia. ${ }^{7}$ As hypocalcaemia and intracranial calcification were detected simultaneously in our patient, when she presented to us with seizures, the above correlation could not be established in our patient.
Disturbances in calcium metabolism may cause metastatic calcification, where calcium is deposited in healthy tissues causing its damage. Evidence suggests that interventions done before tissue damage may protect the tissue and preserve their structural and functional integrity. ${ }^{8}$ It seems that the disturbance of calcium metabolism in our patient had unlikely resulted in irreversible tissue damage causing the features of Parkinsonism or cerebellar dysfunction. This is the key time for the prevention of tissue damage through appropriate interventions.

Our patient had presented with seizure for 6 years. The disturbance of calcium metabolism seems to be chronic. Despite this chronicity, there were no neurological deficits, which may be due to less severe abnormality in the calcium levels and PTH.

Tonic-clonic seizures occurring with hypoparathyroidism have already been reported in literature..$^{9-11}$ Fahr's disease can also attribute to the development of seizure, though the association is extremely rare. ${ }^{12}{ }^{13} \mathrm{In}$ our patient, seizure may be due to intracranial calcification or can be an independent entity. Similarly, the intracranial calcification may be due to Fahr's disease or due to hypoparathyroidism or can be a cumulative effect of both these entities. Evidence suggests that Fahr's disease can be associated with abnormalities in the metabolism of iron, calcium and porphyrin ${ }^{13}$ as well as abnormalities of parathyroid gland. ${ }^{14}$ The existing evidence suggests our diagnosis in this case (Fahr's disease with hypoparathyroidism).

Hypoparathyroidism was diagnosed in our patient on the basis of low-serum ionic calcium and high phosphate levels. There is a need to intervene in this critical period in order to prevent damages to the neuronal tissue of the brain due to metastatic calcification resulting from disturbances of calcium metabolism. This window period may be the crucial period that needs an intensive clinical evaluation and urgent intervention. Correction of underlying metabolic disturbance before damage of neuronal 
tissue due to intracranial calcification may be useful in preventing irreversible neurological deficits.

Contributors JA: data collection, literature review, developed the manuscript, edited the manuscript. BG: concept, developed the manuscript, edited the manuscript. SKK: concept, literature review, developed the manuscript, edited the manuscript.

Funding The authors have not declared a specific grant for this research from any funding agency in the public, commercial or not-for-profit sectors.

Competing interests None declared.

Patient consent for publication Obtained.

Provenance and peer review Not commissioned; externally peer reviewed.

Open access This is an open access article distributed in accordance with the Creative Commons Attribution Non Commercial (CC BY-NC 4.0) license, which permits others to distribute, remix, adapt, build upon this work non-commercially, and license their derivative works on different terms, provided the original work is properly cited, appropriate credit is given, any changes made indicated, and the use is non-commercial. See: http://creativecommons.org/licenses/by-nc/4.0

\section{REFERENCES}

1. Hui JS, Lew MF. Calcification of the basal ganglia. Handb Clin Neurol 2007;84:479-86.

2. Rumboldt Z, Castillo M, Huang B, et al. Brain imaging with MRI and CT: an image pattern approach. Cambridge University Press, 2012.
3. Reeder M, Felson B. Gamuts in radiology, audiovisual radiology of Cincinnati. Cincinnati, Ohio, 1975.

4. Malik R, Pandya V, Naik D. Fahr disease-A rare neurodegenerative disorder. Indian Journal of Radiology and Imaging 2004;14.

5. Manyam BV. What is and what is not 'Fahr's disease'. Parkinsonism Relat Disord 2005;11:73-80.

6. Cartier L, Passig C, Gormaz A, et al. [Neuropsychological and neurophysiological features of Fahr's disease]. Rev Med Chil 2002;130:1383-90.

7. Goswami R, Sharma R, Sreenivas V, et al. Prevalence and progression of basal ganglia calcification and its pathogenic mechanism in patients with idiopathic hypoparathyroidism. Clin Endocrinol 2012;77:200-6.

8. Rizvi I, Ansari NA, Beg M, et al. Widespread intracranial calcification, seizures and extrapyramidal manifestations in a case of hypoparathyroidism. N Am J Med Sci 2012;4.

9. Bindu M, Harinarayana CV. Hypoparathyroidism: a rare treatable cause of epilepsy - report of two cases. Eur J Neurol 2006;13:786-8.

10. Armelisasso C, Vaccario ML, Pontecorvi A, et al. Tonic-clonic seizures in a patient with primary hypoparathyroidism: a case report. Clin EEG Neurosci 2004;35:97-9.

11. Garg RK, Garg N, Tandon N, et al. Idiopathic hypoparathyroidism presenting as epilepsy in a 40 years female. Neurol India 1999;47.

12. Hoque MA, Siddiqui MR, Arafat $Y$, et al. Fahr's disease: a very rare cause of epilepsy. Mymensingh Med J 2010;19:127-9.

13. Beall SS, Patten BM, Mallette L, et al. Abnormal systemic metabolism of iron, porphyrin, and calcium in Fahr's syndrome. Ann Neurol 1989;26:569-75.

14. el Maghraoui A, Birouk N, Zaim A, et al. [Fahr syndrome and dysparathyroidism. 3 cases]. Presse Med 1995;24:1301-4.

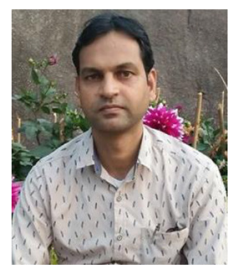

Dr.Jamshed Ahmad graduated and obtained a bachelor degree from the ChhatrapatiShahuJiMaharaj University, Kanpur, India in 2012 and a doctoral degree in psychiatry from the King George Medical University, Lucknow, India in 2017. Now he is working as a senior resident at the department of Psychiatry at the King George Medical University, Lucknow, India. He is also a member of the Indian Psychiatric Society. His research interests include Obsessive Compulsive Disorder and De-addiction Psychiatry. 